\title{
Successful treatment of thyrotoxicosis is accompanied by a decrease in serum sclerostin levels
}

\author{
Elżbieta Skowrońska-Jóźwiak ${ }^{1,2}$, Kinga Krawczyk-Rusiecka ${ }^{1,2}$, Krzysztof C Lewandowski ${ }^{1,2}$, \\ Zbigniew Adamczewski ${ }^{1,2}$ and Andrzej Lewiński, ${ }^{1,2}$
}

\begin{abstract}
Sclerostin, a product of a SOST gene, is a protein expressed by osteocytes that inhibits osteoblastic bone formation. Several hormones, including PTH and glucocorticosteroids, have been suggested to be possible regulators of sclerostin production. The influence of thyroid hormones on sclerostin synthesis has not been investigated, so far. The aim of the study was to evaluate sclerostin concentrations in patients before and after treatment of thyrotoxicosis.
\end{abstract}

Patients and methods: The study involved 15 patients (4 men), mean age $51.8 \pm 15.3$ years, mean BMI value - 24.7 \pm 3.5 , with thyrotoxicosis due to Graves' disease or toxic multinodular goitre. Serum sclerostin was measured by immunoassay at diagnosis of thyrotoxicosis and after 6-10 weeks of treatment with thiamazole. The data were analysed by means of simple descriptive statistics of location and dispersion and Mann-Whitney $U$ test for pairs of results, before and after thiamazole therapy. Association between variables was evaluated with use of Spearman's correlation coefficient.

Results: There was a significant decrease in free $\mathrm{T} 3\left(\mathrm{FT}_{3}\right)$ and free $\mathrm{T} 4\left(\mathrm{FT}_{4}\right)$ concentrations (from $8.74 \pm 4.79 \mathrm{pg} / \mathrm{ml}$ to $3.54 \pm 2.40 \mathrm{pg} / \mathrm{ml}$, and from $4.48 \pm 2.21 \mathrm{ng} / \mathrm{ml}$ to $1.02 \pm 1.07 \mathrm{ng} / \mathrm{ml}$, respectively, $\mathrm{p}<0.001)$. This was accompanied by a marked decrease of serum sclerostin levels from $55.46 \pm 20.90 \mathrm{pmol} / \mathrm{l}$ to $35.73 \pm 15.70 \mathrm{pmol} / \mathrm{l}, \mathrm{p}<0.0015)$. Interestingly, enough, sclerostin levels did not correlate with serum $\mathrm{FT}_{3}$ or $\mathrm{FT}_{4}$ concentrations.

Conclusions: Restoration of a euthyroid state in patients with thyrotoxicosis results in a significant decrease in serum sclerostin concentrations. The above mentioned phenomenon may reflect lowering of bone metabolism, but a possible direct influence of thyroid hormones on SOST gene needs to be investigated.

\section{Background}

Sclerostin, a product of a SOST gene, is a protein expressed by osteocytes and inhibits osteoblastic bone formation. Sclerostin deficiency has been implicated in the pathogenesis of bone sclerosing dysplasias, i.e. sclerosteosis and van Buchem disease [1]. Several hormones have been suggested to serve as possible regulators of sclerostin production. PTH decreased sclerostin production in vitro in mice [2], as well as in vivo in humans [3]. On the other hand, calcitriol alone or in combination with retinoic acid increased SOST expression in human osteoblastic cells

\footnotetext{
* Correspondence: alewin@csk.umed.lodz.pl

'Department of Endocrinology and Metabolic Diseases, Polish Mother's Memorial Hospital - Research Institute, Rzgowska St. No. 281/289, 93-338 Lodz, Poland

${ }^{2}$ Medical University of Lodz, Lodz, Poland
}

in vitro [4]. Glucocorticoids are thought to stimulate sclerostin secretion from osteocytes [5].

The influence of thyroid hormones on sclerostin synthesis has not been investigated so far, however the influence of hypothalamus-pituitary-thyroid axis on bone metabolism is well known [6]. Thyroid hormones are necessary for normal growth. Population studies indicate that both hypothyroidism and hyperthyroidism are associated with an increased risk of fractures [7] .

The aim of the study was to evaluate sclerostin concentrations in patients before and after treatment of thyrotoxicosis.

\section{Patients and methods}

The study was approved by the Ethics Committee of the Polish Mother's Memorial Hospital - Research Institute in 
Table 1 Descriptive statistics for demographic characteristics of the tested sample $(n=15)$

\begin{tabular}{|c|c|c|c|c|c|c|}
\hline & Mean & Median & SD & Min & Max & p-value \\
\hline Age [years] & 51.8 & 59.0 & 15.3 & 18.0 & 69.0 & \\
\hline Body mass - before [kg] & 69.3 & 66.0 & 12.7 & 48.0 & 98.0 & 0.051 \\
\hline Body mass - after [kg] & 70.5 & 72.0 & 12.1 & 51.0 & 98.0 & \\
\hline BMI value - before $\left[\mathrm{kg} / \mathrm{m}^{2}\right]$ & 24.7 & 23.8 & 3.5 & 1.5 & 1.9 & 0.033 \\
\hline BMI value - after $\left[\mathrm{kg} / \mathrm{m}^{2}\right]$ & 25.2 & 25.4 & 3.4 & 19.6 & 31.7 & \\
\hline Heigth & 1.7 & 1.6 & 0.1 & 1.55 & 1.82 & - \\
\hline
\end{tabular}

Lodz, Poland. The study involved 15 patients (4 men), mean age $51.8 \pm 15.3$ years, mean value of BMI $-24.7 \pm 3.5$ $\mathrm{kg} / \mathrm{m}^{2}$, with thyrotoxicosis due to Graves' disease or toxic multinodular goitre. Characteristics of examined population before and after treatment was shown in Table 1. Serum sclerostin was measured by with a quantitative sandwich ELISA by Biomedica (Vienna, Austria) at diagnosis of thyrotoxicosis and after 6-10 weeks of treatment with thiamazole. The intraassay coefficient of variance $(\mathrm{CV})$ is $5 \%$, and the interassay coefficient of variance (CV) is $3-6 \%$. The data were analysed by means of simple descriptive statistics of location and dispersion and Mann-Whitney`s $U$ test for pairs of results before and after thiamazole therapy. Association between variables was evaluated with use of Spearman`s correlation coefficient.

\section{Results}

There was a significant decrease in FT3 and FT4 concentrations (from $8.74 \pm 4.79 \mathrm{pg} / \mathrm{ml}$ to $3.54 \pm 2.40 \mathrm{pg} / \mathrm{ml}$, and from $4.48 \pm 2.21 \mathrm{ng} / \mathrm{ml}$ to $1.02 \pm 1.07 \mathrm{ng} / \mathrm{ml}$, respectively $\mathrm{p}<0.001)$. This was accompanied by a marked decrease of serum sclerostin levels from $55.46 \pm 20.90 \mathrm{pmol} / \mathrm{l}$ to 35.73 $\pm 15.70 \mathrm{pmol} / \mathrm{l}, \mathrm{p}<0.0015$ ) (Table 2). Interestingly, enough, neither sclerostin nor TSH levels did not correlate with serum FT3 or FT4 (Tables 3 and 4).

\section{Discussion}

We demonstrated high levels of sclerostin in thyrotoxicosis and a significant decrease of its serum concentrations coinciding with restoration of an euthyroid state. Pretreatment sclerosin levels in our study were higher than reference values presented by Biomedica (mean concentration - $19.3 \mathrm{pmol} / \mathrm{l}$, range from $10.9 \mathrm{pmol} / \mathrm{l}$ to $28.7 \mathrm{pmol} / \mathrm{l}$ in serum), and by other authors - 33-37 $\mathrm{pmol} / \mathrm{l}$ for healthy premenopausal women [6,7] and 49.8 pmol/l - for men [7].

Thyrotoxicosis is a common endocrine disorder, affecting several systems and organs including skeletal system. Thyrotoxicosis increases bone metabolism and leads to development of osteoporosis [8-10]. Hyperthyroid patients have high bone turnover and negative calcium and phosphorus balance [11]. These detrimental effects of thyrotoxicosis on bone metabolism are probably caused by overproduction of T3, mediated principally by T3 receptor alpha [12] or low TSH level $[13,14]$.

There are several examples of negative impact of thyrototoxicosis on bones even, in subclinical hyperthyroidism, for instance low-normal TSH values are associated with high prevalence of vertebral fractures in women with post-menopausal osteoporosis or osteopenia, independently of thyroid hormones, age and BMD value [13]. This is one of the reasons why in subclinical hyperthyroidism treatment should be considered in the presence of risk factors, including osteoporosis [15].

Influence of thyrotoxicosis on bone seems to be temporary. Fracture risk was only significantly increased around the time of diagnosis but decreased to normal levels after restoration of an euthyroid state $[9,10]$. Furthermore, normalization of BMD, bone markers and osteoprotegerin

Table 2 Descriptive statistics for the measurement results before and after thiamazole therapy (not all subjects have both measurements)

\begin{tabular}{|c|c|c|c|c|c|c|}
\hline & Mean & Median & SD & Min & Max & p-value \\
\hline anti-TPO - before [IU/ml] & 222.7 & 21.8 & 356.0 & 5 & 1000 & - \\
\hline anti-Tg - before [IU/ml] & 109.2 & 20.2 & 222.7 & 10 & 803 & - \\
\hline anti-TSHR - before [IU/I] & 7.6 & 1.3 & 11.6 & 0.3 & 40.0 & 0.999 \\
\hline anti-TSHR - after [IU/I] & 11.9 & 10.9 & 5.9 & 6.6 & 18.3 & \\
\hline TSH - before $[\mathrm{mIU} / \mathrm{I}]$ & 0.0 & 0.0 & 0.0 & 0.0 & 0.0 & 0.013 \\
\hline $\mathrm{TSH}-\operatorname{after}[\mathrm{mlU} / \mathrm{l}]$ & 1.1 & 0.0 & 1.7 & 0.0 & 5.8 & \\
\hline FT3 - before $[\mathrm{pg} / \mathrm{ml}]$ & 8.74 & 7.53 & 4.79 & 4.02 & 16.5 & 0.0010 \\
\hline FT3 - after $[\mathrm{pg} / \mathrm{ml}]$ & 3.49 & 3.54 & 2.40 & 0.74 & 4.8 & \\
\hline FT4 - before $[\mathrm{ng} / \mathrm{ml}]$ & 4.48 & 2.21 & 1.01 & 7.84 & 32.5 & 0.0010 \\
\hline FT4 - after $[\mathrm{ng} / \mathrm{ml}]$ & 1.02 & 1.07 & 0.44 & 0.34 & 1.7 & \\
\hline Sclerostin- before [pmol/l] & 55.46 & 41.90 & 20.90 & 39.29 & 148.8 & 0.0015 \\
\hline Sclerostin - after [pmol/l] & 35.73 & 27.20 & 15.70 & 23.46 & 99.6 & \\
\hline
\end{tabular}

P-value for the Mann-Whitney`s $U$ test for a comparison of pairs of measurement results before and after antithyroid therapy (where appropriate). 
Table 3 Spearman rang correlation coefficients $\left(r_{s}\right)$ for FT3 (before and after) and other measurement results

\begin{tabular}{lccccc}
\hline & \multicolumn{2}{c}{ FT3 - before } & & \multicolumn{2}{c}{ FT3 - after } \\
\cline { 2 - 3 } \cline { 6 - 6 } & $\mathbf{r}_{\mathbf{s}}$ & $\mathbf{p}$-value & & $\mathbf{r}_{\mathbf{s}}$ & $\mathbf{p}$-value \\
\hline TSH & 0.535 & 0.040 & & -0.464 & 0.094 \\
\hline Sclerostin & 0.079 & 0.781 & & 0.064 & 0.829 \\
\hline
\end{tabular}

Table 4 Spearman rang correlation coefficients $\left(r_{s}\right)$ for FT4 (before and after) and other measurement results

\begin{tabular}{lccccc}
\hline & \multicolumn{2}{c}{ FT4 - before } & & \multicolumn{2}{c}{ FT4 - after } \\
\cline { 2 - 3 } \cline { 6 - 6 } & $\mathbf{r}_{\mathbf{s}}$ & $\mathbf{p}$-value & & $\mathbf{r}_{\mathbf{s}}$ & $\mathbf{p}$-value \\
\hline TSH & 0.252 & 0.365 & & -0.489 & 0.076 \\
\hline Sclerostin & -0.004 & 0.990 & & 0.240 & 0.409 \\
\hline
\end{tabular}

was observed during treatment $[10,11,16]$, however, some authors showed elevation of bone formation markers despite normalization of thyroid hormones and TSH levels $[10,17]$. We speculate that a decrease of sclerostin levels as observed by us - may be associated with normalization of bone metabolism. It may also be argued that the above mentioned decrease in sclerostin levels in patients recovering from thyrotoxicosis might be mediated by $\mathrm{PTH}$. This is because a fall of PTH concentration was reported in subjects with thyrotoxicosis $[10,17]$, followed by an increase during anti-thyroid treatment [11]. There are also recent data demonstrating a decline of sclerostin concentrations by PTH. For instance, lowering of sclerostin levels was demonstrated after injection of PTH [3] and in patients with hyperparathyroidism $[18,19]$. Supposing the normalization of thyroid hormones is accompanied by an increase of $\mathrm{PTH}$, one might argue that $\mathrm{PTH}$ per se might be responsible for the decline of sclerostin concentrations observed, in our study.

To the best of our knowledge, this study is the first in which a clear decrease in sclerostin concentrations resulting presumably from a decrease of thyroid function has been demonstrated. The cause of this phenomenon is, however, complex and requires further study.

\section{Competing interests}

The authors declare that they have no competing interests.

\section{Authors' contributions}

ES-J designed the study, qualified the patients and prepared the draft of manuscript. KK-R and ZA qualified the patients and participated in data acquisition and in performing hormonal studies. KCL participated in acquisition of data and the scientific revision of the manuscript. $A L$, the senior author, wrote the final version of manuscript. All authors read and approved the final manuscript.

\section{Acknowledgements}

Special thanks to Dr Malgorzata Bienkiewicz from the Department of Quality Control and Radiation Protection, The Medical University of Lodz, for her help in preparing statistical analysis. The study was financially supported by funds from the Polish Mother's Memorial Hospital - Research Institute (project no. 2011N/3) and from the Medical University of Lodz, Poland (project no. 502-03/1-107-03/502-14-087).

Received: 26 September 2012 Accepted: 2 November 2012

Published: 13 November 2012

\section{References}

1. Moester MJC, Papapoulos SE, Löwik CWGM, van Bezooijen RL: Sclerostin: current knowledge and future perspectives. Calcif Tissue Int 2010, 87:99-107.

2. Bellido T, Ali AA, Gubrij I, Plotkin LI, Fu Q, O'Brien CA, Manolagas SC, Jilka RL: Chronic elevation of parathyroid hormone in mice reduces expression of sclerostin by osteocytes: a novel mechanism for hormonal control of osteoblastogenesis. Endocrinology 2005, 146:4577-4583.

3. Yu EW, Kumbhani R, Siwila-Sackman E, Leder BZ: Acute decline in serum sclerostin in response to PTH infusion in healthy men. J Clin Endocrinol Metab 2011, 96:E1848-E1851.

4. Sutherland MK, Geoghegan JC, Yu C, Winkler DG, Latham JA: Unique regulation of SOST, the sclerosteosis gene, by BMPs and steroid hormones in human osteoblasts. Bone 2004, 35:448-454.

5. La Corte R, Trotta F, Adami S: Glucocorticoid receptors and bone. Curr Pharm Des 2010, 16:3586-3592.

6. Ardawi MS, Al-Kadi HA, Rouzi AA, Qari MH: Determinants of serum sclerostin in healthy pre- and postmenopausal women. J Bone Miner Res 2011, 26:2812-2822.

7. Amrein K, Amrein S, Drexler C, Dimai HP, Dobnig H, Pfeifer K, Tomaschitz A, Pieber TR, Fahrleitner-Pammer A: Sclerostin and its association with physical activity, age, gender, body composition, and bone mineral content in healthy adults. J Clin Endocrinol Metab 2012, 97:148-154.

8. Pantazi H, Papapetrou PD: Changes in parameters of bone and mineral metabolism during therapy for hyperthyroidism. J Clin Endocrinol Metab 2000, 85:1099-1106.

9. Vestergaard P, Mosekilde L: Fractures in patients with hyperthyroidism and hypothyroidism: a nationwide follow-up study in 16,249 patients. Thyroid 2002, 12:411-419.

10. Kumeda Y, Inaba M, Tahara H, Kurioka Y, Ishikawa T, Morii H, Nishizawa Y: Persistent increase in bone turnover in Graves' patients with subclinical hyperthyroidism. J Clin Endocrinol Metab 2000, 85:4157-4161.

11. Nagasaka S, Sugimoto H, Nakamura T, Kusaka I, Fujisawa G, Sakuma N, Tsuboi Y, Fukuda S, Honda K, Okada K, Ishikawa S, Saito T: Antithyroid therapy improves bony manifestations and bone metabolic markers in patients with Graves' thyrotoxicosis. Clin Endocrinol (Oxf) 1997, 47:215-221.

12. Williams GR: Actions of thyroid hormones in bone. Endokrynol Pol 2009, 60:380-388.

13. Mazziotti G, Porcelli T, Patelli I, Vescovi PP, Giustina A: Serum TSH values and risk of vertebral fractures in euthyroid post-menopausal women with low bone mineral density. Bone 2010, 46:747-751.

14. Ma R, Morshed S, Latif R, Zaidi M, Davies TF: The influence of thyroidstimulating hormone and thyroid-stimulating hormone receptor antibodies on osteoclastogenesis. Thyroid 2011, 21:897-906.

15. Wiersinga WM: Should we treat mild subclinical/mild hyperthyroidism? Yes. Eur J Intern Med 2011, 22:324-329.

16. Amato G, Mazziotti G, Sorvillo F, Piscopo M, Lalli E, Biondi B, lorio S, Molinari A, Giustina A, Carella C: High serum osteoprotegerin levels in patients with hyperthyroidism: effect of medical treatment. Bone 2004, 35:785-791.

17. Bouillon R, DeMoor P: Parathyroid function in patients with hyper- or hypothyroidism. J Clin Endocrinol Metab 1974, 38:999-1004.

18. Ardawi MS, Al-Sibiany AM, Bakhsh TM, Rouzi AA, Qari MH: Decreased serum sclerostin levels in patients with primary hyperparathyroidism: a crosssectional and a longitudinal study. Osteoporos Int 2012, 23:1789-1797.

19. Costa AG, Cremers S, Rubin MR, McMahon DJ, Sliney J Jr, Lazaretti-Castro M, Silverberg SJ, Bilezikian JP: Circulating sclerostin in disorders of parathyroid gland function. J Clin Endocrinol Metab 2011, 96:3804-3810.

doi:10.1186/1756-6614-5-14

Cite this article as: Skowrońska-Jóźwiak et al: Successful treatment of thyrotoxicosis is accompanied by a decrease in serum sclerostin levels. Thyroid Research 2012 5:14. 